\title{
Functional Outcome in Delusional Alzheimer Disease Patients
}

\section{A Systematic Review}

\author{
Corinne E. Fischer ${ }^{a, b}$ Nicolaas P.L.G. Verhoeff ${ }^{b, c}$ Katie Churchill ${ }^{a, d}$ \\ Tom A. Schweizer ${ }^{\mathrm{a}, \mathrm{e}}$ \\ ${ }^{a}$ Keenan Research Centre, Li Ka Shing Knowledge Institute, St. Michael's Hospital, ${ }^{b}$ Department of Psychiatry, \\ 'Baycrest Hospital, d Department of Occupational Health and Occupational Sciences, and e Department of Surgery, \\ Division of Neurosurgery, University of Toronto, Toronto, Ont., Canada
}

\section{Key Words}

Delusions $\cdot$ Psychosis $\cdot$ Elderly $\cdot$ Dementia $\cdot$ Alzheimer's disease $\cdot$ Function $\cdot$ Activities of daily living, independent

\begin{abstract}
Background: In spite of the prevalence of delusions in Alzheimer's disease (AD) and their association with poor outcomes, there has been little study of the impact of delusions on real-world functioning. Method: A number of databases, including Psychlit and Medline, were searched using the keywords: delusions, functional outcomes, activities of daily living, dementia, and Alzheimer's disease. Studies were included in the review if they were in English, restricted to patients with $A D$, and addressed delusions and function. $\boldsymbol{R e}$ sults: The review yielded a total of 6 studies, 3 of which showed a correlation between delusions and real-world functioning and 3 of which did not. Conclusion: A critical analysis of the existing studies suggests that there may be an association between delusions and impaired real-world functioning. We believe that 2 of the 3 negative studies did not show an association due to issues relating to study design and the use of measures insensitive to executive impairment. This review highlights the future need for more scientifically rigorous studies to clarify this association, so as to ultimately improve treatment outcomes for patients.
\end{abstract}

Copyright $\odot 2009$ S. Karger AG, Basel

\section{Introduction}

Alzheimer's disease (AD) is a neurodegenerative condition associated with changes in cognition, real-world functioning and behaviour. Many studies have examined the impact of various factors on functional impairment in $\mathrm{AD}$. One of the most extensively studied variables has been cognitive performance itself, with functional performance correlating with a decline in cognitive performance [1-4]. The majority of studies have shown a nonlinear relationship between cognition and real-world functioning, suggesting that while a relationship exists, other important factors may modify this relationship.

Other studies have attempted to determine which neurocognitive factors are most predictive of functional impairment. More recent studies have implicated certain neuropsychological deficits, most significantly executive impairment [5-8]. Intact executive cognitive processing is required to perform many daily functions, such as planning, organizing and multitasking. Royall et al. [7, 8] studied the impact of executive impairment on real-world functioning, both cross-sectionally and prospectively, in a large cohort of community-dwelling seniors. The results showed that executive impairment was independently associated both with the presence of functional impairment and with the rate of decline specifically in instrumental activities of daily living (IADL) after con-

\section{KARGER \\ Fax +41613061234 E-Mail karger@karger.ch} www.karger.com
Dr. Corinne Fischer

rm17044, 17 Cardinal Carter Wing, St. Michael's Hospital

30 Bond Street

Toronto, Ont. M5B 1W8 (Canada)

Tel. +1 416864 5320, Fax +1 416864 5480, E-Mail fischerc@smh.toronto.on.ca 
trolling for other variables that could potentially affect real-world functioning. Swanberg et al. [6] conducted a retrospective study and discovered that $\mathrm{AD}$ patients with greater executive impairment, as measured by a combination of cancellation tasks and the maze subtest from the ADAS-Cog, had worse function a year later when compared to $\mathrm{AD}$ patients with less executive impairment. Evidence for the impact of other neurocognitive variables has been less robust. Edwards et al. [9] found constructional apraxia correlated with increasing functional impairment among outpatients with AD. The role of visuospatial impairment has been less clear, with 1 study showing a correlation [10] and 1 study [11] which showed no effect. Similarly, the impact of memory is inconclusive, with a recent study suggesting a correlation with semantic memory, but no impact of auditory-verbal short-term or episodic memory on functional performance [10].

Real-world functioning in $\mathrm{AD}$ may also be impaired by a number of non-cognitive factors. As older patients often develop $\mathrm{AD}$, other factors related to aging such as physical or sensory impairment may play an indirect role. $\mathrm{AD}$ is also associated with the development of a number of psychiatric symptoms that may contribute to functional impairment. Both the presence of psychosis and depression in the absence of dementia may be associated with functional decline. Few studies have examined this phenomenon in $\mathrm{AD}$ patients, but in those that have, a relationship has been established [12-14], especially when combined with cognitive factors. As most behavioural symptoms emerge with increasing cognitive decline, it has been difficult in these studies to separate out how much decline can be attributed to the symptoms themselves and how much can be attributed to the associated decline in cognition.

Delusions are well documented in $\mathrm{AD}$, with an estimated prevalence of $36 \%$ [15]. Incidence rates are more controversial as many of the studies that examined incidence did not differentiate delusions from hallucinations when evaluating psychotic symptoms. This distinction is of paramount importance given that it is now well understood that delusions and hallucinations have a separate neuroanatomical basis [16-18]. However, Paulsen et al. [19] did report a 1-year incidence rate of $20 \%$ for psychosis. Previously published studies have also suggested that delusions, like many neurobehavioural symptoms in dementia, may fluctuate [20]. Delusions, in addition to being common, are clinically important symptoms in $\mathrm{AD}$ as studies have shown them to be associated with a number of adverse outcomes, including increased caregiver stress and premature institutionalization [21, 22]. Studies linking delusions to functional performance, however, are lacking.

There are a number of potential reasons why delusions might be expected to be associated with worse real-world functioning. Delusions are often associated with other neurobehavioural symptoms, such as depression and hallucinations, which may also be linked to poor functional performance. Studies to date have suggested that AD patients with delusions are likely to progress more rapidly when compared to AD patients without delusions [19], suggesting as well more rapid functional decline. Some investigators have even suggested that $\mathrm{AD}$ patients may be empirically divided into separate categories based on the existence of behavioural symptoms such as delusions or psychosis [23]. Specifically, Ropacki and Jeste [15] have suggested that Alzheimer patients with delusions should be regarded as a more aggressive subtype of the disease, given the association with more moderate cognitive impairment and more rapid cognitive decline. Others [18] have suggested that this may not be the case given that delusions may commonly co-exist with other behavioural symptoms and are unlikely to occur in isolation. One of the most compelling arguments, which may explain both the link to poor functional performance and more rapid cognitive decline, is the relationship between delusions and frontal lobe functioning. As discussed, real-world functioning in $\mathrm{AD}$ appears very much linked to executive cognitive processing. Delusions have been linked neuroanatomically, in many studies, to abnormalities in the frontal lobes. Binetti et al. [17] compared CT scans of AD patients with and without delusions and found a significant difference in the number of frontal lobe white matter lesions among the delusional $\mathrm{AD}$ patients compared to non-delusional controls. Functional neuroimaging studies conducted using SPECT scans have demonstrated hypoperfusion in the frontal lobes among delusional $\mathrm{AD}$ patients when compared to age- and disease-matched non-delusional controls [16, 24]. Kotrla et al. [16] showed relatively greater hypoperfusion in the left frontal lobe compared to the right, while Mega et al. [24] also showed hypoperfusion in the frontal cortex as well as the adjacent parietal and subcortical structures. A recent PET study conducted by Sultzer et al. [25] examined cerebral glucose metabolism in AD patients with delusions, and concluded that delusional severity may be linked neurophysiologically with changes in the right prefrontal cortex. Neuropathological studies have confirmed these findings, suggesting a higher density of senile plaques in the frontal lobes of $\mathrm{AD}$ patients with delusions compared to age- and disease-matched controls [26], specifically in 
Table 1. Delusions and functional outcome studies

\begin{tabular}{|c|c|c|c|}
\hline $\begin{array}{l}\text { Journal } \\
\text { citation }\end{array}$ & Study design & Psychiatric scales & Outcome \\
\hline $\begin{array}{l}\text { Green } \\
\text { et al. [33] }\end{array}$ & $\begin{array}{l}\text { prospective study of } 149 \text { patients } \\
\text { evaluated at multiple memory clinics } \\
\text { in New York City }\end{array}$ & ADAS-NC & $\begin{array}{l}\text { after controlling for the variance associated with } \\
\text { cognitive impairment, there was no significant } \\
\text { correlation between the presence of delusions and } \\
\text { functional impairment as measured by the PSMS } \\
\text { and IADL scales }\end{array}$ \\
\hline $\begin{array}{l}\text { Harwood } \\
\text { et al. [34] }\end{array}$ & $\begin{array}{l}\text { prospective study of } 114 \mathrm{AD} \text { patients } \\
\text { evaluated consecutively at an outpatient } \\
\text { memory disorders clinic }\end{array}$ & $\begin{array}{l}\text { BEHAVE-AD, } \\
\text { RMBPC, BDS, MMSE }\end{array}$ & $\begin{array}{l}\text { after controlling for the variance associated } \\
\text { with MMSE, delusions correlated with function } \\
(\mathrm{p}<0.05) \text { as measured by the BDS }\end{array}$ \\
\hline $\begin{array}{l}\text { Tekin } \\
\text { et al. [35] }\end{array}$ & $\begin{array}{l}\text { retrospective study of } 143 \text { outpatients } \\
\text { with probable AD }\end{array}$ & $\begin{array}{l}\text { FAQ, NPI, MMSE, } \\
\text { CIRS-G }\end{array}$ & $\begin{array}{l}\text { function as measured by the FAQ correlated } \\
\text { significantly with the NPI and } 9 \text { of the } 10 \text { subscores, } \\
\text { including delusions }(\mathrm{p}<0.05)\end{array}$ \\
\hline $\begin{array}{l}\text { Mok } \\
\text { et al. [36] }\end{array}$ & $\begin{array}{l}\text { retrospective study of } 100 \text { outpatients } \\
\text { with Alzheimer's disease seen at the } \\
\text { Memory Clinic of Queen Mary Hospital }\end{array}$ & $\begin{array}{l}\text { CDR, NPI, MMSE, } \\
\text { ADL, IADL }\end{array}$ & $\begin{array}{l}\text { hallucinations and disinhibition scores correlated } \\
\text { inversely with ADL, while hallucinations and aber- } \\
\text { rant motor activity correlated inversely with IADL }\end{array}$ \\
\hline $\begin{array}{l}\text { Weiner } \\
\text { et al. [35] }\end{array}$ & $\begin{array}{l}\text { retrospective database study of } 100 \\
\text { autopsy-confirmed AD cases }\end{array}$ & CDR, MMSE & $\begin{array}{l}\text { no significant correlation between the CDR score and } \\
\text { delusions }(\mathrm{p}=0.54)\end{array}$ \\
\hline $\begin{array}{l}\text { Liu } \\
\text { et al. }[38]\end{array}$ & $\begin{array}{l}\text { prospective study of } 142 \text { consecutive } \\
\text { AD patients from an outpatient memory } \\
\text { disorders clinic }\end{array}$ & $\begin{array}{l}\text { CDR, Barthel Index, } \\
\text { Alzheimer's Deficit } \\
\text { Scale, BEHAVE-AD }\end{array}$ & $\begin{array}{l}\text { presence of delusions, as measured by the BEHAVE- } \\
\text { AD, was significantly correlated with function, as } \\
\text { measured by the Barthel Index }(\mathrm{p}<0.05)\end{array}$ \\
\hline
\end{tabular}

ADAS-NC = Alzheimer's Disease Assessment Scale (non-cognitive subscale); PSMS = Physical and Self-Maintenance Scale; IADL = Lawton's Instrumental Activities of Daily Living; BEHAVE-AD = Behavioral Pathology in Alzheimer's Disease; RMBPC = Revised Memory and Behavior Problem Checklist; MMSE = Mini Mental State Exam; FAQ = Functional Activities Questionnaire; NPI = Neuropsychiatric Inventory; CIRS-G = Cumulative Illness Rating Scale-Geriatrics; CDR = Clinical Dementia Rating Scale; $\mathrm{ADL}=$ Barthel Activities of Daily Living.

the mid-frontal and presubiculum regions. Neuropsychological studies have largely supported these findings. Studies conducted to date have suggested in general greater neuropsychological impairment among delusional AD patients [19, 27-32], with more deficits in classic executive (frontal lobe) tasks [19, 31].

The question of whether or not delusions are associated with greater functional impairment has some very practical implications. Knowing this association would allow physicians and policy makers to develop interventions that would better target psychotic symptoms, leading to improved patient functional outcomes. The purpose of this review is to examine whether or not delusions are associated cross-sectionally with worse functional performance. We will attempt to do this by reviewing existing studies that have explored the relationship between real-world functioning and delusions. This will be followed by a discussion of possible explanations of our findings and their implications for future research.

\section{Methods}

Various medical databases, including Medline and Psychlit, were searched using the keywords: delusions, functional outcomes, activities of daily living, dementia and Alzheimer's disease. Studies were included in the review if they were available in English, involved patients with AD and delusions, and involved a minimum of 1 functional and 1 psychiatric scale. Studies that were longitudinal, did not distinguish delusions from hallucinations and included patients with other forms of dementia (such as Parkinson's disease, dementia with Lewy bodies, vascular dementia and frontal-temporal dementia) were excluded.

\section{Results}

Review of the literature yielded 6 citations that met the specified inclusion and exclusion criteria (table 1). Three of the studies were retrospective [35-37], and 3 were prospective in design $[33,34,38]$. The vast majority used the MMSE as the main cognitive measure while behavioural 
and functional measures varied considerably across studies. Most of the studies used sample sizes averaging approximately 100 patients and were recruited from memory disorder clinics.

\section{Discussion}

Of the 6 studies meeting the specified inclusion and exclusion criteria [33-38], 3 showed a positive correlation between real-world functioning and the presence of delusions [34, 35, 38]. Two of the 3 studies which failed to show a positive correlation $[36,37]$ were retrospective in design, and this may have impacted on the results. Retrospective identification of delusions may be problematic, particularly if standardized scales are not used to detect the presence of delusions at the time the patients are assessed. Both patients and caregivers may be reluctant to volunteer this information unless specifically asked. Weiner et al. [37] studied autopsy-confirmed AD cases, but behavioural symptoms were arrived at through retrospective chart analysis, rather than through administration of discrete scales. As symptoms were not identified in any systematic way and the interpretation may have been variable, this may have confounded the results. Furthermore, the functional scale selected was the Clinical Dementia Rating Scale (CDR), a scale that looks less at specific IADL performance and more at global performance. Thus, subtle deficits in real-world functioning mediated by executive cognitive processing may not have been as apparent. The results obtained from the study by Mok et al. [36] are somewhat harder to explain. Clearly, the patient sample $(\mathrm{n}=100)$ was adequate and behavioural symptoms were detected through administration of standardized scales. Two functional scales, the Barthel Index (measuring activities of daily living; ADL) and the Lawton's IADL score were used, covering the entire spectrum of daily functions. One would at least anticipate some correlation between the IADL scale and delusions, but this proved negative. The negative results of this study may again relate to the difficulty in accurately documenting the presence of delusions retrospectively. Notably, hallucinations again correlated well with overall functional performance as measured by the Barthel Index, and poorly with scales measuring more complex functions. Finally, the study by Green et al. [33] (although prospective in design, having an adequate sample size and using appropriate scales) failed to show a correlation, not only between delusions and functional ability, but also between behavioural symptoms in general and func- tional ability. This study had some unique aspects which may have affected the results. First, single patient visits were used to establish the presence of behavioural symptoms. Thus, patients may have been identified as delusional without meeting any minimum time criterion. Second, other confounding factors, including use of psychotropic medication, were controlled for. As use of psychotropic medication may correlate with behavioural symptoms, this may have adversely affected the association.

Of the 3 studies showing a positive correlation, only 1 study [34] controlled for the confounding effects of impaired cognition. This is important as delusions have been shown in multiple studies to correlate with overall decline in cognitive functioning. Therefore, to prove it is in fact the presence of delusions and not the associated decline in cognition that is associated with impairment in daily function, it is important to control for the effects of impaired cognitive processing. The study of Harwood et al. [34] also showed an association between the presence of hallucinations and function as measured by the Blessed Dementia Scale (BDS). The BDS is a measure of function that looks at changes in everyday activities, such as spending money, basic habits (such as using the toilet) and changes in personality (such as coarsening of affect). It is possible that the Harwood et al. study [34], although showing a positive correlation between delusions and real-world functioning, may have actually underestimated the impact of delusions on real-world functioning given that the BDS does not address functions mediated by executive cognitive processing such as planning a shopping trip or preparing a meal. The study by Tekin et al. [35], although retrospective in design, did focus on IADL as opposed to ADL. This may partially explain the positive results, given the link to executive processing demands. The study by Liu et al. [38] was one of the few studies using the Barthel Index that showed a positive correlation between delusions and real-world functioning. It is hard to know how much this positive result could be related to discrepancies in overall cognitive processing.

One would anticipate, based on what we know about the correlation between delusions and executive cognitive processing, that functional measures which focus on these frontal lobe functions would be the most likely to show a difference. Only studies by Green et al. [33], Mok et al. [36] and Tekin et al. [35] used scales that focused on IADL performance (the Lawton IADL scale and the FAQ). However, only 1 of these studies showed a positive correlation [35]. Harwood et al. [34] used the BDS, a scale 
that incorporates little measurement of executive cognitive processing. The positive results obtained in this study may in fact underestimate the true impact of delusions on real-world functioning. Both Weiner et al. [37] and Liu et al. [38] used fairly basic scales, including the Barthel and the CDR scale. However, only Liu's study [36] showed a positive correlation.

The majority of the studies looked at other behavioural symptoms, in addition to delusions, and the results are of interest. Green et al. [33] showed no correlation between the presence of behavioural symptoms and functional impairment. Mok et al. [36] found no correlation between behavioural symptoms, as measured by the NPI, and functional impairment. They did, however, show a relationship with hallucinations. Harwood et al. [34] found a correlation with both delusions and hallucinations, but not with other behavioural symptoms. Weiner et al. [37] found that all behavioural symptoms correlated, including delusions, as did Tekin et al. [35] and Liu [38]. Thus, it is not clear from the disparity of findings whether or not other behavioural symptoms are the major driving force behind the associated functional decline.

While most of the studies alluded to in this review were scientifically sound, some limitations should be pointed out. Many of the studies used very basic measures of functional performance (i.e. looking at basic functional tasks such as grooming, toileting) that did not incorporate those functions mediated by executive cognitive processing. These studies could have potentially underestimated the impact of delusions on functional performance. Furthermore, the studies varied in terms of their ability to deal with confounders linked to poor functional outcome such as age, socioeconomic status, medical comorbidity and, perhaps most importantly, cognitive impairment itself. Only the studies by Green et al. [33] and Harwood et al. [34] attempted to take into account the variance associated with cognition. In addition, the studies varied considerably in terms of how they defined a 'delusion'. Many of the studies sought caregiver input and used different rating scales. As delusions have been known to fluctuate considerably over time, it would be important for there to be a minimum time criterion from the onset of the delusion to time of testing. Finally, with the exception of the study by Green et al. [33], none of the studies alluded to the use of psychoactive medications, such as antipsychotic medications or cognitive enhancers, which may independently affect real-world functioning.

\section{Conclusion}

In conclusion, this review suggests that delusions may be associated with worse functional performance in patients with Alzheimer's disease. The full extent of the impact of delusions on functional performance in most studies performed to date may actually be underestimated. As demonstrated, most of the studies have relied on functional scales that emphasize basic tasks as opposed to more complex tasks. Furthermore, few of the studies attempted to account for the variance associated with cognition, and most used very basic measures of cognition which lacked sensitivity, possibly leading to inaccurate results. Specifically, none of the studies used measures of executive cognitive impairment which may have correlated well with the decline in function based on previous research. Data captured about the delusions was limited in terms of severity and duration. Finally, the studies examined in the course of this review were all cross-sectional in nature - no longitudinal studies were analyzed. Future studies could improve on these limitations by incorporating more detail about delusional severity, conducting more longitudinal studies, and using cognitive and functional measures that are better at detecting executive impairment.

\section{Acknowledgements}

The authors would like to gratefully acknowledge the Alzheimer society of Canada for their support.

References

Dement Geriatr Cogn Disord 2009;27:105-110 
$\checkmark 5$ Boyle PA, Malloy PF, Salloway S, CahnWeiner DA, Cohen R, Cummings JL: Executive dysfunction and apathy predict functional impairment in Alzheimer's disease. Am J Geriatr Psychiatry 2003;11:214-221.

-6 Swanberg MM, Tractenberg RE, Mohs R, Thal LJ, Cummings JL: Executive dysfunction in Alzheimer's disease. Arch Neurol 2004;6:556-560.

7 Royall DR, Chiodo LK, Polk MJ: Correlates of disability among elderly retirees with subclinical cognitive impairment. J Gerontol A Biol Sci Med Sci 2000;55:M541-M546.

$\checkmark 8$ Royall DR, Lauterbach EC, Cummings JL, Reeve A, Rummans TA, Kaufer DI, LaFrance WC, Coffey CE: Executive control function: a review of its promise and challenges for clinical research. A report from the Committee on Research of the American Neuropsychiatric Association. J Neuropsychiatry Clin Neurosci 2002; 14:377-405.

9 Edwards DF, Baum CM, Duel RK: Constructional apraxia in Alzheimer's disease: contributions to functional loss; in Taira ED (ed): The Mentally Impaired Elderly: Strategies and Interventions to Maintain Function, ed 2. Binghamton, Haworth Press, 1991, pp 5368.

$>10$ Perry RJ, Hodges JR: Relationship between functional and neuropsychological performance in early Alzheimer disease. Alzheimer Dis Assoc Disord 2000;14:1-10.

-11 Liu CJ, McDowd J, Lin KC: Visuospatial inattention and daily life performance in people with Alzheimer's disease. Am J Occup Ther 2004;58:202-210.

12 Levy ML, Cummings JL, Fairbanks LA, Bravi D, Calvani M, Carta A: Longitudinal assessment of symptoms of depression, agitation, and psychosis in 181 patients with Alzheimer's disease. Am J Psychiatry 1996; 135:1438-1443.

-13 Ballard C, Bannister C, Solis M, Oyebode F, Wilcock G: The prevalence, associations and symptoms of depression amongst dementia sufferers. J Affect Disord 1996;36:135-144.

14 Forsell Y, Windblad B: Major depression in a population of demented and nondemented older people: prevalence and correlates. J Am Geriatr Soc 1998;46:27-30.

15 Ropacki S, Jeste D: Epidemiology of and risk factors for psychosis of Alzheimer's disease: a review of 55 studies. Am J Psychiatry 2005; 162:2022-2030.
16 Kotrla KJ, Chacko RC, Harper RG, Jhingran S, Doody R: SPECT findings on psychosis in Alzheimer's disease. Am J Psychiatry 1995; 152:1470-1475.

17 Binetti G, Padovani A, Magni E, Bianchetti A, Scuratti A, Lenzi GL, Trabucchi M: Delusions and dementia: clinical and CT correlates. Acta Neurol Scand 1995;91:271-275.

18 Bassiony MM, Lyketsos C: Delusions and hallucinations in Alzheimer's disease: review of the brain decade. Psychosomatics 2003;44:388-401.

19 Paulsen JS, Salmon DP, Thal LJ, Romero R, Weisstein-Jenkins C, Galasko D, et al: Incidence and risk factors for delusions and hallucinations in patients with probable AD. Neurology 2000;54:1965-1971.

20 Devanand DP, Jacobs DM, Tang MX, Del Castillo-Casteneda C, Sano M: The course of psychopathologic features in mild to moderate Alzheimer disease. Arch Gen Psychiatry 1997;54:257-263.

21 Gormley N, Rizwan MR, Lovestone S: Clinical predictors of aggressive behaviour in Alzheimer's disease. Int J Geriatr Psychiatry 1998;13:109-115.

22 Harwood DG, Barker WW, Ownby RL, Duara R: Prevalence and correlates of Capgras syndrome in Alzheimer's disease. Int J Geriatr Psychiatry 1999;14:415-420.

23 Lyketsos CG, Sheppard JM, Steinberg M, Tschanz JA, Norton MC, Steffens DC, Breitner JC: Neuropsychiatric disturbance in Alzheimer's disease clusters into three groups: the Cache County Study. Int J Geriatr Psychiatry 2001;16:1043-1053.

24 Mega MS, Lee L, Dinov ID, Mishkin F, Toga AW, Cummings JL: Cerebral correlates of psychotic symptoms in Alzheimer's disease. J Neurol Neurosurg Psychiatry 2000;69:167171.

25 Sultzer DL, Brown CV, Mandelkern MA, Mahler ME, Mendez MF, Chen ST, Cummings JL: Delusional thoughts and regional frontal/temporal cortex metabolism in $\mathrm{Alz}$ heimer's disease. Am J Psychiatry 2003;160 341-349.

-26 Zubenko GS, Moossy J, Martinez AJ, et al: Neuropathologic and neurochemical correlates of psychosis in primary dementia. Arch Neurol 1991;48:619-624.

27 Fischer C, Ladowsky-Brooks R, Millikin C, Norris M, Hansen K, Rourke SB: Neuropsychological functioning and delusions in dementia: a pilot study. Aging Ment Health 2006;10:27-32.
28 Flynn FG, Cummings JL, Gornbein J: Delusions in dementia syndromes: investigation of behavioral and neuropsychological correlates. J Neuropsychiatry Clin Neurosci 1991; 3:364-370.

29 Haupt M, Kurz A: Predictors of nursing home placement in patients with Alzheimer's disease. Int J Geriatr Psychiatry 1993; 8:741-746.

30 Jeste DV, Wragg RE, Salmon DP, Harris MJ, Thal LJ: Cognitive deficits of patients with Alzheimer's disease with and without delusions. Am J Psychiatry 1992;149:184-189.

31 Lopez OL, Brenner RP, Becker JT, Ulrich RF, Boiler F, Dekosky ST: EEG spectral abnormalities and psychosis as predictors of cognitive and functional decline in probable Alzheimer's disease. Neurology 1997;48: 1521-1525.

-32 Rockwell E, Jackson E, Vilke G, Jeste D: A study of delusions in a large cohort of Alzheimer's disease patients. Am J Geriatr Psychiatry 1994;2:157-164.

33 Green CR, Marin DB, Mohs RC, Schmeidler J, Aryan M, Fine E, Davis KL: The impact of behavioral impairment of functional ability in Alzheimer's disease. Int J Geriatr Psychiatry 1999;14:307-316.

>34 Harwood DG, Barker WW, Ownby RL, Duara R: Relationship of behavioural and psychological symptoms to cognitive impairment and functional status in Alzheimer's disease. Int J Geriat Psychiatry 2000;15:393400 .

35 Tekin S, Fairbanks LA, O’Connor S, Rosenberg S, Cummings JL: Activities of daily living in Alzheimer's disease: neuropsychiatric, cognitive and medical influences. Am J Geriatr Psychiatry 2001;9:81-86.

36 Mok WY, Chu LW, Chung CP, Chan NY, Hui SL: The relationship between non-cognitive symptoms and functional impairment in Alzheimer's disease. Int J Geriatr Psychiatry 2004;19:1040-1046.

37 Weiner MF, Hynan LS, Bret ME, White C 3rd: Early behavioral symptoms and course of Alzheimer's disease. Acta Psychiatr Scand 2005;111:367-371.

38 Liu CY, Wang PN, Lin KN, Liu HS: Behavioural and psychological symptoms in Taiwanese patients with Alzheimer's disease. Int Psychogeriatr 2007;19:605-613. 